\title{
Local anesthetic systemic toxicity in children: a review of recent case reports and current literature - an infographic
}

\author{
Rajnish K Gupta (10 , ${ }^{1}$ Eric S Schwenk (10 ${ }^{2}$
}

\section{SUMMARY}

Local anesthetic systemic toxicity (LAST) in children is an understudied complication of regional anesthesia but is uniquely different in many ways when compared with adult LAST. The estimated risk of LAST in children is $8 / 100,000(95 \% \mathrm{CI}$, 0.3 to 1.6 ) whereas that risk in adults is approximately $27 / 100,000$. In this review of the literature and case reports, Ramesh and Boretsky discovered that $68 \%$ of LAST events in children occurred under general anesthesia and only $42 \%$ received lipid emulsion as treatment. ${ }^{1}$ Ultrasound was not used in $87 \%$ of the cases when LAST occurred and a vascular marker (epinephrine) was not used in $84 \%$ of cases. Over half of the cases were in children under 3 years of age with $73 \%$ occurring in males. Penile blocks, caudal blocks, and dental local infiltrations represented the most frequent procedures where toxicity occurred. Notably, dentists and primary care physicians are more likely to use greater than the maximum recommended dosage of local anesthetic.

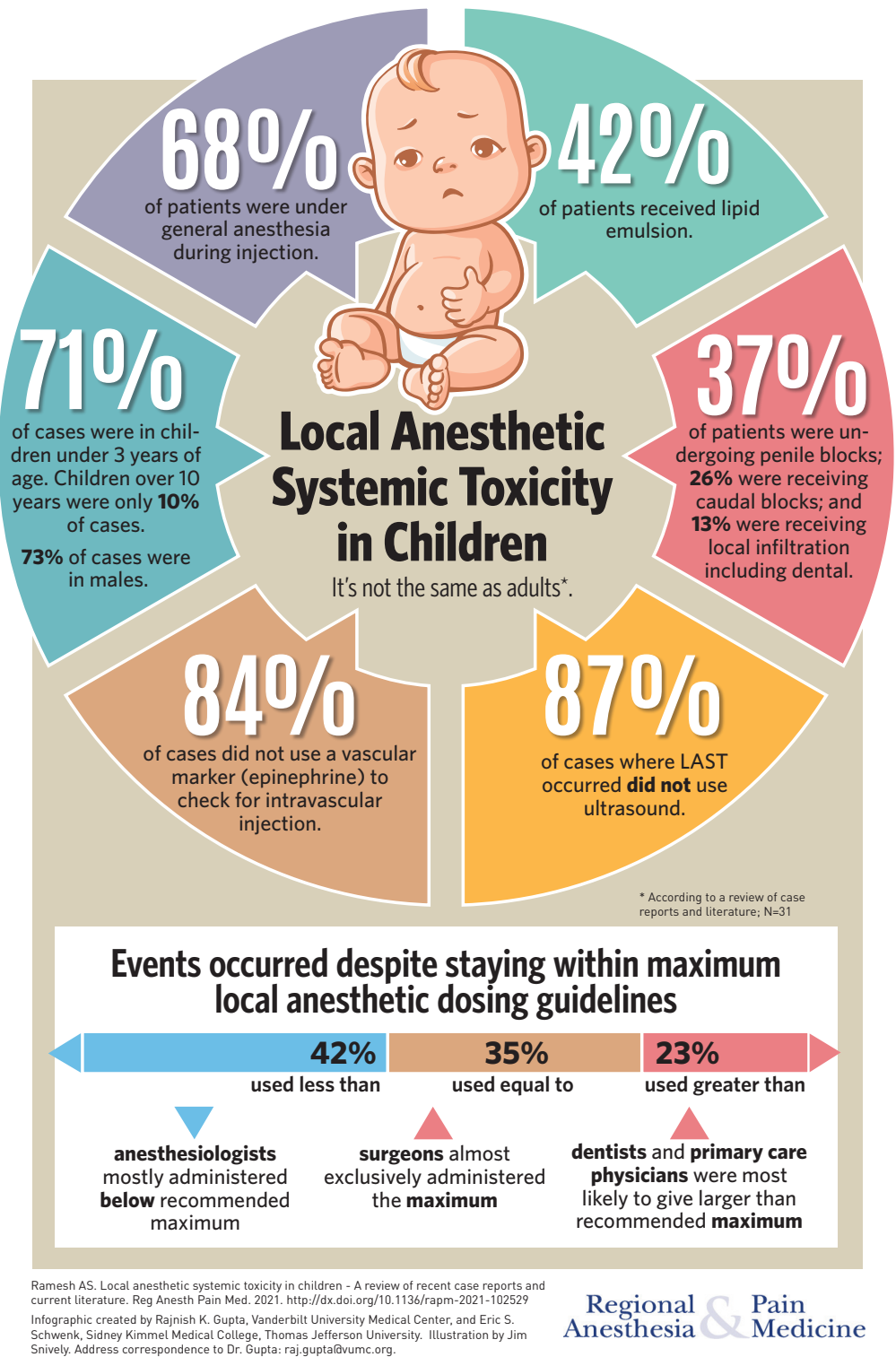

${ }^{1}$ Anesthesiology, Vanderbilt University Medical Center, Nashville, Tennessee, USA

${ }^{2}$ Anesthesiology, Sidney Kimmel Medical College at Thomas Jefferson University, Philadelphia, Pennsylvania, USA

Correspondence to Dr Rajnish K Gupta, Anesthesiology, Vanderbilt University Medical Center, Nashville, TN 37232, USA; raj.gupta@vumc.org

Correction notice This article has been corrected since it published Online First. The infographic image has been corrected.

Twitter Rajnish K Gupta @dr_rajgupta and Eric S Schwenk @ESchwenkMD

Acknowledgements We would like to acknowledge Jim Snively, artist, of Pittsburgh, PA, for creation of this infographic.

Collaborators Jim Snively

Contributors I provided the editing and content for the infographic along with design ideas and concept.

Funding The authors have not declared a specific grant for this research from any funding agency in the public, commercial or not-for-profit sectors.

Competing interests Both coauthors are associate editors for Regional Anesthesia and Pain Medicine.

Patient consent for publication Not required.

Provenance and peer review Commissioned; internally peer reviewed.

(c) American Society of Regional Anesthesia \& Pain Medicine 2021. No commercial re-use. See rights and permissions. Published by BMJ.

A) Check for updates

To cite Gupta RK, Schwenk ES. Reg Anesth Pain Med 2021;46:915.

Received 25 June 2021

Accepted 26 June 2021

Published Online First 6 July 2021

\section{S Linked}

- http://dx.doi.org/10.1136/rapm-2021-102529

Reg Anesth Pain Med 2021;46:915.

doi:10.1136/rapm-2021-102993

ORCID iDs

Rajnish K Gupta http://orcid.org/0000-0003-34014737

Eric S Schwenk http://orcid.org/0000-0003-3464-4149

\section{REFERENCE}

1 Singaravelu Ramesh A, Boretsky K. Local anesthetic systemic toxicity in children: a review of recent case reports and current literature. Reg Anesth Pain Med 2021;46:909-14 